\title{
Nanoscale microenvironment engineering for expanding human hair follicle stem cell and revealing their plasticity
}

\author{
Peng Chen ${ }^{\dagger}$, Feifei Zhang ${ }^{\dagger}$, Zhexiang Fan, Tianding Shen, Bingcheng Liu, Ruosi Chen, Qian Qu, Jin Wang ${ }^{*}$,
} Yong Miao ${ }^{*}$ and Zhiqi Hu* (D)

\begin{abstract}
Background: Periodically regenerated hair follicles provide an excellent research model for studying tissue regeneration and stem cell homeostasis. Periodic activation and differentiation of hair follicle stem cells (HFSCs) fuel cyclical bouts of hair regeneration. HFSCs represent an excellent paradigm for studying tissue regeneration and somatic stem cell homeostasis. However, these crucial studies are hampered by the lack of a culture system able to stably expand human HFSCs and regulate their fate.
\end{abstract}

Results: Here, we use layer-by-layer (LbL) self-assembly with gelatin/alginate to construct a nanoscale biomimetic extracellular matrix (ECM) for an HFSC population. The LbL coating provides ECM and mechanical support for individual cells, which helps to maintain the $\mathrm{CD}_{200^{+}} \mathrm{a} 6^{+} \mathrm{HFSC}$ population to a certain extent. Addition of key signal molecules (FGF-7 and VEGF-A) simulates the minimum essential components of the stem cell microenvironment, thereby effectively and stably expanding HFSCs and maintaining the CD200 ${ }^{+} a 6^{+} \mathrm{HFSC}$ population. Subsequently, BMP2 loaded to the nanocoated layer, as a slow-release signal molecule, activates BMP signaling to regulate HFSCs' fate in order to obtain a purified CD200+ $a 6^{+}$HFSC population.

Conclusion: This system can minimize the microenvironment of HFSCs; thus, stably amplifying HFSCs and revealing their plasticity. Our study thus provides a new tool for studies of hair follicle reconstruction and stem cell homeostasis.

Keywords: Human hair follicle stem cells, Stem cell microenvironment, Layer-by-layer self-assembly, Regenerative medicine, Tissue engineering

\section{Background}

Human adult stem cells (SCs) are critical for tissue homeostasis, repair, and regeneration [1,2]. The distinct capabilities of SCs to self-renew and differentiate are central for the maintenance of organ homeostasis [3]. SCs are under strict homeostatic regulation, so that the system

*Correspondence: drwangjin@126.com; doctormiao0371@163.com huzhiqidr@163.com

'Peng Chen and Feifei Zhang contributed equally to this work Department of Plastic and Aesthetic Surgery, Nanfang Hospital, Southern Medical University, 1838 North Guangzhou Avenue, Guangzhou 510515, Guangdong, China can adapt rapidly to interference to restore tissue function effectively. Human hair follicles are considered miniorgans with periodic regeneration and abundant sources, providing an attractive model for the tissue homeostasis and regeneration research.

The cyclical bouts of hair regeneration, growth (anagen), regression (catagen), and rest (telogen) are driven by the quiescent activation cycle of hair follicle stem cells (HFSCs) [4]. HFSCs are the key seed cells for tissue hair follicle reconstruction and provide an excellent paradigm for the study of somatic adult SC lineage [1]. Thus far, crucial studies have been hindered by the lack of a culture system able to expand human HFSCs and stably

(c) The Author(s) 2021. This article is licensed under a Creative Commons Attribution 4.0 International License, which permits use, sharing, adaptation, distribution and reproduction in any medium or format, as long as you give appropriate credit to the original author(s) and the source, provide a link to the Creative Commons licence, and indicate if changes were made. The images or other third party material in this article are included in the article's Creative Commons licence, unless indicated otherwise in a credit line to the material. If material is not included in the article's Creative Commons licence and your intended use is not permitted by statutory regulation or exceeds the permitted use, you will need to obtain permission directly from the copyright holder. To view a copy of this licence, visit http://creativecommons.org/licenses/by/4.0/. The Creative Commons Public Domain Dedication waiver (http://creativecommons.org/publicdomain/zero/1.0/) applies to the data made available in this article, unless otherwise stated in a credit line to the data. 
regulate their fate. Whereas various culture systems are dedicated to culturing HFSCs in vitro [5-7], there are no methods to maintain and expand true pluripotent human HFSCs in culture without fibroblast feeder cells, as well as in vitro methods for regulating the fate of human HFSCs and their progeny.

$\mathrm{SCs}$ are present in spatially distinct microenvironments, known as niches. The niches of SC comprise SCs themselves, neighboring cells, signals, and the extracellular matrix (ECM) [8]. In in vitro culture, SCs abandon their niche microenvironment and rapidly lose their distinct properties [9]. Previously, Chacón-Martínez et al. [10] established an in vitro culture system based on a 3D ECM environment and defined soluble factors that allowed murine HFSCs to expand and self-sustain on a long-term without heterologous cell types. However, whether the system is suitable for the culture of human HFSCs remains unknown. Besides, due to the hypoxia in the spheroid and contact inhibition in 3D culture, and the difficulty of digestion and passage, 3D culture for largescale expansion of HFSCs is still hindered. Previously, we successfully constructed a $2 \mathrm{D}$ biomimetic microenvironment for mouse HFSCs that helped maintain the SC property of mouse HFSCs and regulate their fate to an extent [11]. Hence, exploring biomaterials to mimic SC microenvironments in 2D culture systems, amplify multipotent HFSCs, and regulate their fate, has become a promising solution for tissue homeostasis and regeneration studies.

Layer-by-layer (LbL) self-assembly as a thin film manufacturing technology for cell surface coating. This technique deposits a multilayer of nanocoating on the cell surface with oppositely charged polycationic and polyanion materials [12-14]. Due to the tunability and versatility of the coating layers, LbL cell coating has been successfully developed for various biomedical applications, such as cell-based biosensors [15], targeted gene therapy [16], cell/molecular delivery [17, 18], and tissue engineering [19]. LbL is different from other technologies for encapsulating cells into micro-hydrogels, which usually produce large cell aggregates and cannot control the mechanical properties of hydrogels. LbL can construct a biomimetic ECM for cells at the single-cell level and control the mechanical properties of the coating to provide mechanical support for the cells. Additionally, gelatin is a protein derivative, while alginate derived from algae. Because of their biodegradability and biocompatibility, these two biomaterials have been widely applied in ECM engineering [20-23]. Here, we applied LbL self-assembly with gelatin/alginate to coat human HFSCs for ECM engineering and maintain HFSC properties.

In vitro culture of human HFSCs usually requires extracting the outer root sheath cells (ORSCs) from the hair follicle, which are subsequently seeded on a feeder layer after fluorescence-activated cell sorting (FACS) of the bulge $\left(\mathrm{CD}^{2} 20^{+} \alpha 6^{+}\right)$HFSCs. This usually requires a large number of human hair follicles to obtain a tiny amount of purified CD200 $\alpha 6^{+}$HFSCs. Several studies have shown the plasticity of HFSCs even though the bulge normally produces hair germ; thus, the hair germ can replenish an empty bulge niche, which underscores their close relationship and capacity to interconvert when required [1, 24]. Moreover, studies have reported on the plasticity of mouse HFSCs in vitro with the addition of BMP or SHH inhibitors [10, 11]. However, no studies on the plasticity of human HFSCs in vitro exist. Furthermore, LbL self-assembly technology effectively regulates cell functions by loading certain bioactive macromolecules to the nanocoated layer $[25,26]$. However, whether we can load active factors into LbL nanocoating for regulating the fate of human HFSCs and reveal their plasticity requires further verification.

Therefore, our study aimed to develop a novel 2D culture model by constructing a nanoscale microenvironment for HFSCs to expand human HFSCs and reveal their plasticity. To this end, we first isolated and extracted human HFSCs, and verified whether the LbL nanocoating of gelatin/alginate could be used for human HFSCs for constructing a nanoscale ECM. Then, we studied how LbL nanocoating based on single cells affects human HFSCs' viability, proliferation, morphology, and SC properties. We also added defined factors to the medium to study the key factors required to reconstruct the essential components of the HFSC microenvironment. Finally, we loaded BMP2 to the nanocoated layer to study whether the nanocoated layer can act as a drug carrier for regulating HFSCs' fate further to obtain CD200 $\alpha 6^{+}$HFSCs. Our 2D biomimetic culture system construct allowed human HFSCs to be expanded and maintained without feeder cells for tissue homeostasis and regeneration studies. Based on this system, we also revealed the plasticity of human HFSCs, providing a cellular mechanism for homeostatic regulation of the SC microenvironment.

\section{Results \\ Isolation and culture of human HFSCs}

To construct a biomimetic microenvironment for HFSCs in vitro, we first isolated and cultured HFSCs. Freshly isolated ORSCs from human hair follicles con-

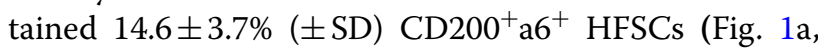
b). The isolated ORSC suspension was then cultured in standard 2D culture condition with keratinocyte growth medium (KGM) on the fibroblast feeder layer, which is widely used in keratinocyte culture [10, 27]. As shown in Fig. 1c, under this culture condition, the cell grew well at P0; however, the cell morphology changed and 


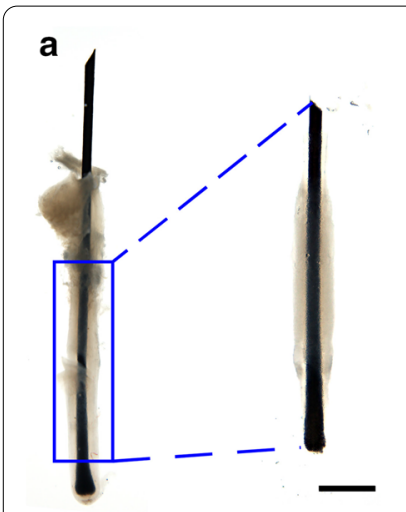

d
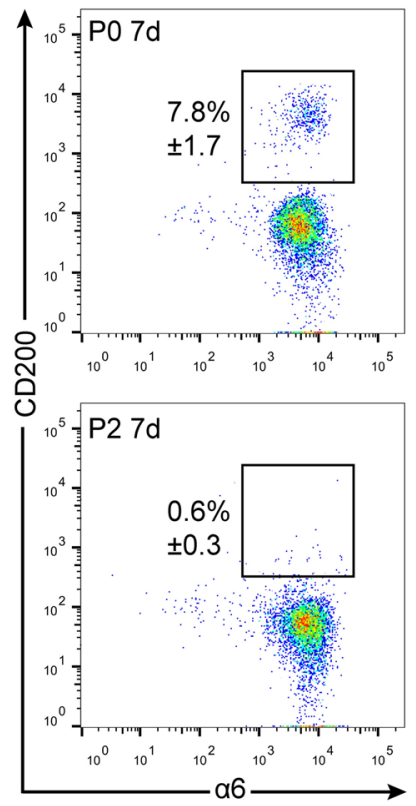

e

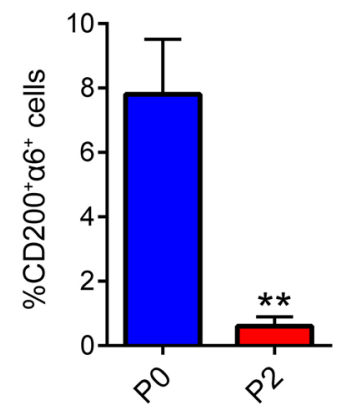

b

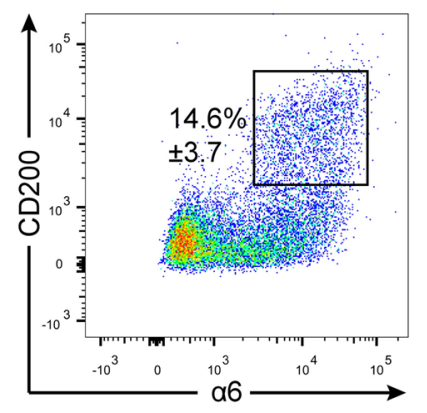

f
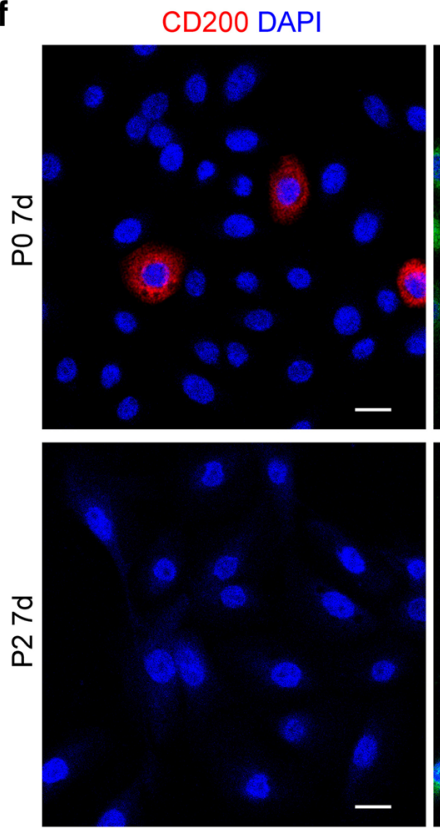

g

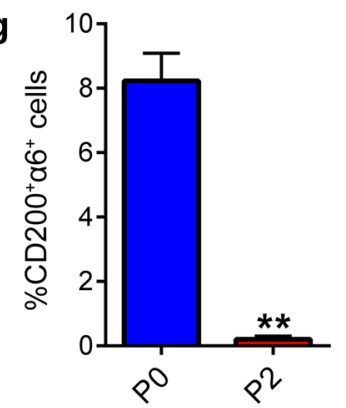

c
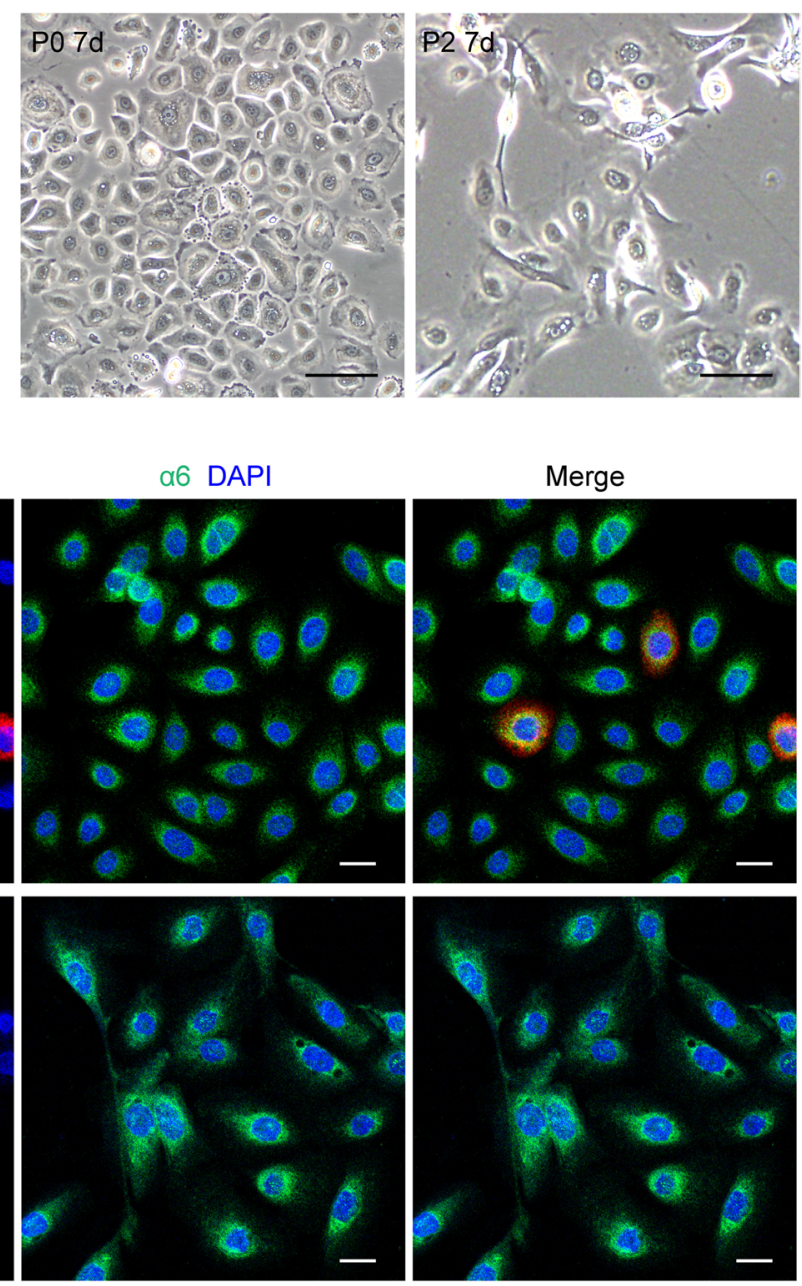

Fig. 1 Culture of human HFSCs under standard 2D culture conditions. a After microscopic separation combined with enzyme digestion, the remaining hair follicle tissue containing the outer root sheath was obtained. Scale bars: $200 \mu \mathrm{m}$. b Flow cytometry analysis showed that the proportion of $\mathrm{CD}_{200} \mathrm{ab}^{+} \mathrm{HFSC}$ in freshly isolated HFSCs from human hair follicles was $14.6 \% \pm 3.7 \%( \pm$ SD). $\mathbf{c}$ The growth status of HFSCs was examined using a microscope in passage 0 (P0) and passage 2 (P2) under standard 2D culture conditions. Scale bars:200 $\mu$ m. d, e Flow cytometry was performed on day 7 after culture. The results showed that CD200 $a 6^{+} \mathrm{HFSCs}$ were significantly down-regulated under standard 2D culture conditions, and that no CD200 ${ }^{+} 6^{+}$HFSCs were present in P2 (mean $\pm S D ; n=3 ;{ }^{* *} p<0.01$, Student's t-test). $\mathbf{f}, \mathbf{g}$ Immunofluorescence staining was conducted on day 7 after culture, and the results showed that the proportion of $C D 200^{+} a 6^{+}$cells decreased significantly under standard $2 \mathrm{D}$ culture conditions. No red-stained CD200+ HFSCs were present at P2 (mean \pm SD; $n=4 ;{ }^{* *} p<0.01$, Student's t-test). DAPI (blue); CD200 (red); a6 (green); Scale bars: $20 \mu \mathrm{m}$ 
proliferation declined after passage P2, and cells could not be passaged. The cloning formation assay further confirmed that the proliferation of HFSCs at P2 was significantly lower than that at P0 (Additional file 1: Figure S1). Flow cytometry and immunofluorescence staining analysis showed that the $\mathrm{CD} 200^{+} \alpha 6^{+}$HFSC population of the cells grown under these conditions was depleted after culture (Fig. 1d-g). These results indicate that under standard 2D culture conditions, HFSCs rapidly lose their proliferation ability and SC properties.

\section{LbL nanocoated HFSCs and their characterization in vitro} ECM components are crucial in directing the proliferation, migration and polarity, differentiation, and status of SCs [28]. Some ECM components play an important role in ensuring the SCs remain undifferentiated [29-31]. Natural ECM polysaccharides and proteins can be used as scaffolds to create a natural ECM-like environment, which mimics the mechanical and physical properties required for the niches of SCs in vivo [32]. First, we used LbL nanocoating technology to coat human HFSCs with gelatin and alginate to construct a single-cell-based nanoscale ECM (Fig. 2a). Next, we used FITC-conjugated gelatin/rhodamine $\mathrm{B}$-conjugated alginate to observe the LbL nanocoating on the surface of the HFSCs. From the results, each nanocoated layer displayed relevant green or red fluorescence (Fig. 2b). The cell size did not change significantly after each nanocoating step (Fig. 2c). In addition, the duration of the coating biomaterial on the cell surface was observed by coating HFSCs with (gelatinFITC)-alginate-gelatin (Fig. 2d). The fluorescence intensity on the cell surface gradually decreased over time from 0 to 10 days, which indicated that the biomaterials were gradually degraded and could be maintained for about 7 days, thereby supplying adequate time for their applications and functions. Moreover, a zeta-potential analysis was performed to evaluate the potential cell changes in different layers of the nanocoating (Fig. 2e). The zeta potential varies with different levels of biomaterials. Oppositely charged polyelectrolytes are combined with each other and deposited. The results indicate that LbL nanocoating by gelatin/alginate was applied to human HFSCs successfully.

\section{LbL coating as a scaffold maintained the spheroid-like morphology of HFSCs without affecting cell viability and proliferation}

After successfully using LbL to coat a single HFSC (with gelatin and alginate used to construct a biomimetic ECM), we examined how LbL nanocoating using gelatin/ alginate affects HFSCs' viability, proliferation, and morphology. On the third and seventh days after LbL nanocoating, live/dead staining results showed low cell death rates of untreated and LbL-treated HFSC. There was no significant difference between the two groups $(p>0.05$; Fig. 3a, b). These data indicate that the nanoscale ECM produced by LbL cell nanocoating was not harmful to the viability of HFSCs. Immunostaining for Ki-67 was subsequently performed on days 3 and 7 after coating to evaluate the proliferation of HFSCs in the two groups (Fig. 3c). As shown in Fig. 3d, no significant difference was detected $(p>0.05)$. SEM analysis was carried out on both groups on days 1, 3, and 7 after LbL nanocoating to evaluate the cell morphology (Fig. 3e). The LbL-coated HFSCs exhibited a spheroid morphology at an early time point after coating, while those that were uncoated exhibited a broadly stretched morphology. However, on day 7 after coating, there was no significant difference between the two groups $((p>0.05$; Fig. $2 f)$, indicating that LbL coating as a scaffold can provide mechanical support for HFSCs to morphologically display more in vivo-like $3 \mathrm{D}$ structures at an early time point after coating.

\section{LbL coating helped maintain the CD200 $a \sigma^{+} \mathrm{HFSC}$ population}

Subsequently, we examined the effect of LbL nanocoating on the properties of human HFSCs. Freshly isolated primary HFSCs were cultured with or without LbL coating, and the LbL-coated group was subsequently coated with LbL during each passage. After 7 days of culture, flow cytometry and immunofluorescence staining were carried out to detect the proportion of CD200 ${ }^{+} \alpha 6^{+}$HFSCs at P0 and P2 (Figs. 3c and 4a). As shown in Fig. 4b, d, the proportion of $\mathrm{CD} 200^{+} \alpha 6^{+}$cells in the LbL-HFSCs was higher than in the uncoated HFSCs. In the uncoated HFSCs, CD200 ${ }^{+} \alpha 6^{+}$cells completely disappeared in P2 and could not be further passaged. qRT-PCR and Western blot results were consistent with the above results. The expression of CD200 mRNA and protein of LbLHFSCs at P0 or P2 was higher than that of uncoated HFSCs (Additional file 1: Figure S2). Besides, after further passage, the LbL-HFSCs maintained the proportion of $\mathrm{CD}_{200^{+}} \alpha 6^{+}$to some extent (Fig. 4e). These results suggest that the ECM constructed by LbL coating with gelatin/alginate can maintain the $\mathrm{CD}_{200}{ }^{+} \alpha 6^{+}$HFSC population.

\section{Key growth factors stabilize the $\mathrm{CD}_{200^{+}} \mathrm{a6^{+ }}$ HFSC population}

Notably, the $\mathrm{CD} 200^{+} \alpha 6^{+}$HFSC population remained low, regardless of the standard 2D culture conditions or the LbL coating group, which is unsatisfactory for the requirements of further research. Therefore, we aimed to reconstruct the essential components of the HFSC microenvironment in vitro by using the knowledge of signal conduction research in the HFSC microenvironment 


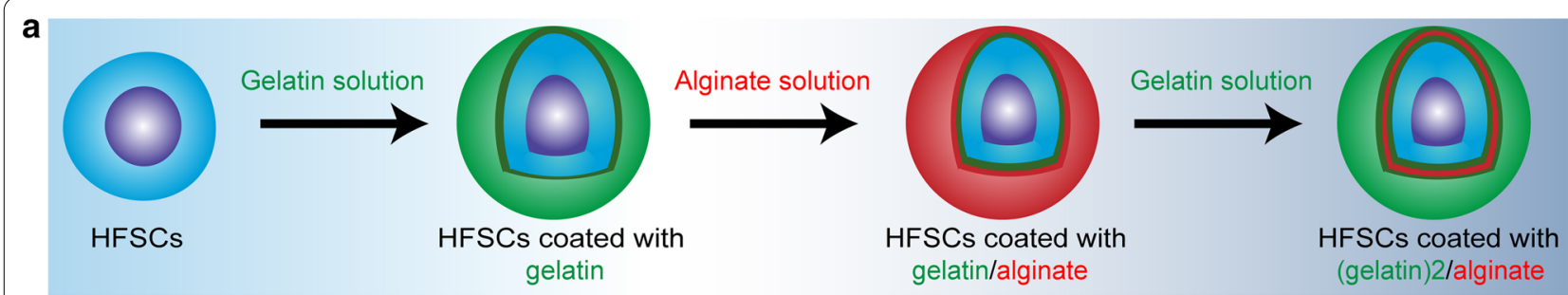

b
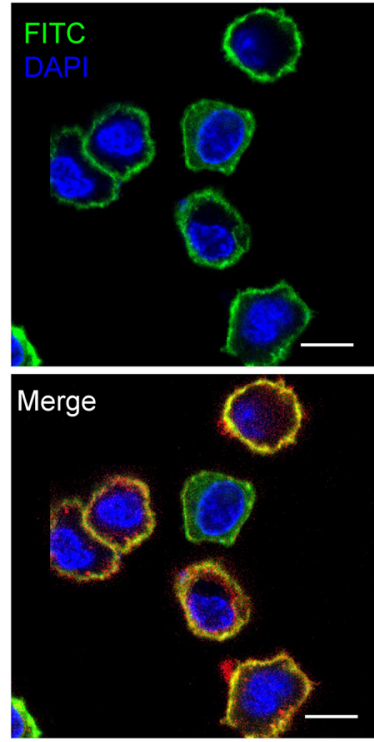

C

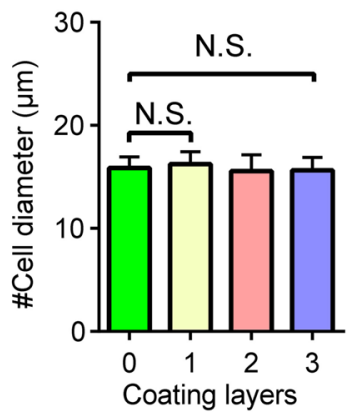

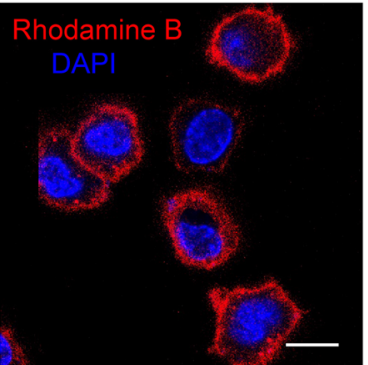

d
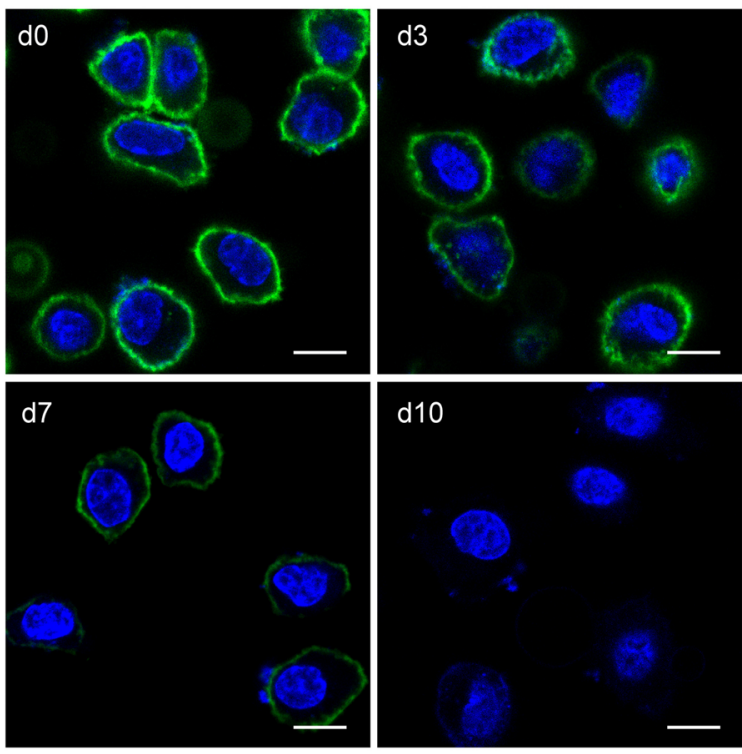

d10

e

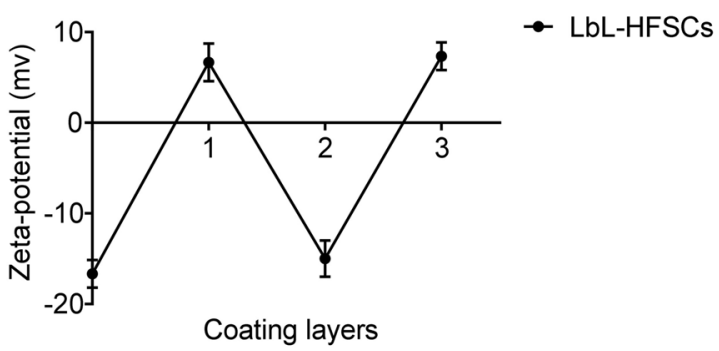

Fig. 2 Generation of LbL-HFSCs based on the LbL cell nanocoating technique. a Schematic diagram of coating human HFSCs to construct LbL-HFSCs. b Images of confocal laser scanning microscopy (CLSM) show the HFSCs coated with gelatin-FITC (green)/alginate-rhodamine B (red). The cells are in suspension. DAPI (blue). Scale: $10 \mu \mathrm{m}$. c The cell diameter after different nanocoating layer was calculated using Image-Pro Plus 6.0 based on the images of CLSM (mean $\pm S D ; n=4$; NS, not significant; $p>0.05$, one-way ANOVA). $\mathbf{d}$ CLSM images displaying the existence of the biomaterials coated on the surface of the HFSCs by LBL. The cells are in suspension. DAPI (blue); Gelatin-FITC (green); scale: $10 \mu \mathrm{m}$. e Zeta-potential changes per cell surface coating layer (mean $\pm S D ; n=4)$ : (0) uncoated HFSCs, (1) gelatin-coated HFSCs, (2) gelatin/alginate- coated HFSCs, (3) (gelatin) 2/alginate- coated HFSCs

in vivo. Studies have shown that several growth factors, such as FGF and VEGF-A, which are expressed in hair follicles and regulate their growth [33-35]. After that, we added FGF-7 and VEGF-A to the medium to observe the changes in the $\mathrm{CD}_{200} \alpha 6^{+}$HFSC population. Flow cytometry and immunofluorescence staining detected the ratio of $\mathrm{CD} 200^{+} \alpha 6^{+}$HFSC in each group at
P2 (Fig. 5a, c). As shown in Fig. 5b, d, the proportion of $\mathrm{CD}^{200}{ }^{+} \mathrm{a}^{+}$HFSC population in LbL-HFSCs containing FGF7 and VEGF-A (hereinafter, LbL-HFSCs + FV) was significantly upregulated. Moreover, the absolute number of CD200 ${ }^{+} \alpha 6^{+}$HFSCs in LbL-HFSCs + FV increased eightfold for cultures at $\mathrm{P} 2$, which was much higher than that in the other groups (Fig. 5e). However, even if 


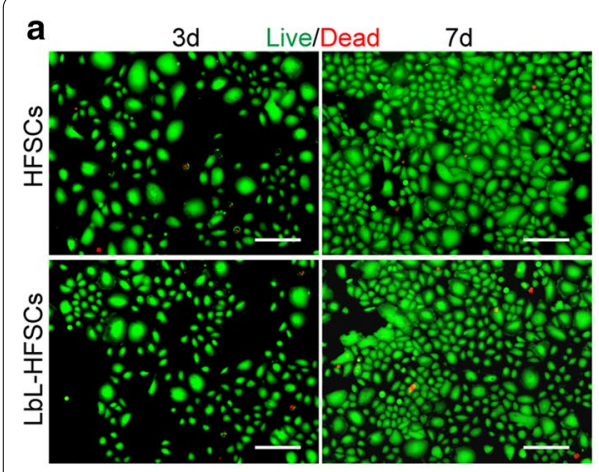

b

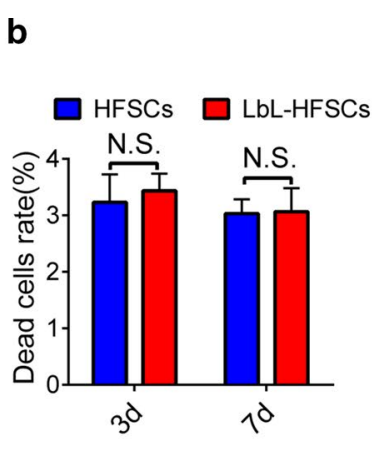

d

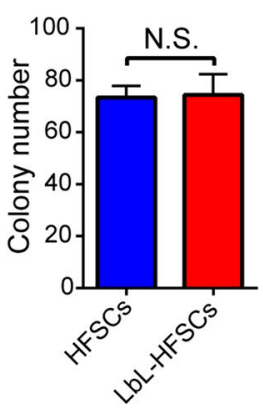

e

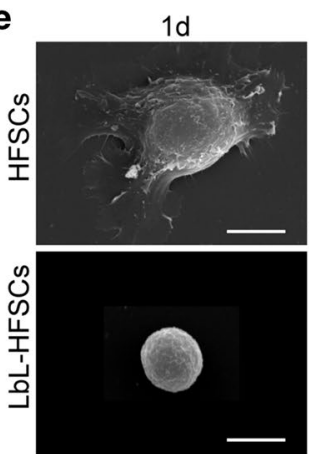

C

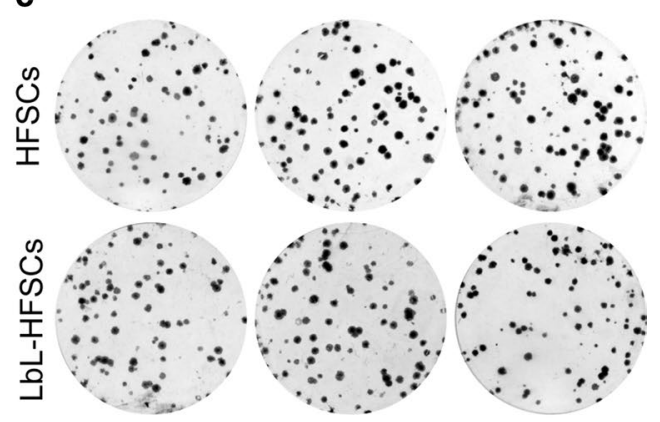

$7 d$
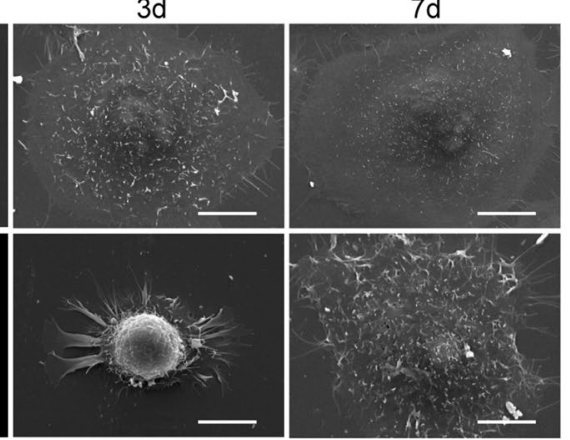

f
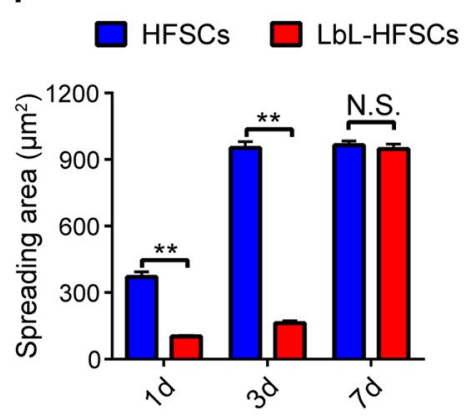

Fig. 3 The effect of LBL coating on HFSCs'viability, proliferation, or morphology. a Live/dead staining shows the dead cells in the uncoated HFSCs and LbL-coated HFSCS on days 3 and 7 of culture. Dead (red); Live (green); Scale bars: $100 \mu \mathrm{m}$. b There was no significant difference in the proportion of dead cells between uncoated HFSCs and LbL-HFSCs (mean \pm SD; $n=4 ;$ NS, not significant; $p>0.05$, Student's t-test). c Colony formation assays detected the effect of LbL coating on the proliferation of HFSCs. $\mathbf{d}$ Number of clones between the uncoated HFSCs and LbL-coated HFSCs. No significant difference was observed (mean $\pm S D ; n=4 ; N S$, not significant; $p>0.05$, Student's t-test). e The morphology of uncoated HFSCs and LbL-HFSCs on day 1, 3, and 7 was evaluated by SEM. Scale bars: $10 \mu \mathrm{m}$. $\mathbf{f}$ On days 1 and 3 after coating, the stretched area of the HFSCs was calculated using Image-Pro Plus 6.0 based on the SEM results. The stretched area of the LbL-coated HFSCs was lower than that of the uncoated HFSCs; however, on day 7, there was no significant difference (mean $\pm S D ; n=4 ; N S$, not significant; $p>0.05,{ }^{* *} p<0.01$, Student's t-test)

FGF7 and VEGF-A were added to the uncoated group, the $\mathrm{CD} 200^{+} \alpha 6^{+}$HFSC population still disappeared rapidly. This indicates the importance of the gelatin + alginate ECM construct in maintaining the $\mathrm{CD}^{2} 00^{+} \alpha 6^{+}$ HFSC population. Surprisingly, the LbL-HFSCs + FV group can be passaged every 7 days. Moreover, the level of $\mathrm{CD} 200^{+} \alpha 6^{+}$HFSCs from P2 remained unchanged (Fig. 5f). Overall, these data indicate that the culture conditions of LbL-HFSCs + FV mimic the conditions of the $\mathrm{SC}$ microenvironment in stably maintaining and expanding the $200^{+} \alpha 6^{+}$HFSC population.

\section{LbL coating-sustained release of BMP2 mediates the plasticity of SC to obtain CD200 ${ }^{+} a 6^{+}$HFSC population}

Subsequently, we tried applying known signaling pathways that mediate the transition between HFSCs and their progeny to obtain more purified $\mathrm{CD} 200^{+} \alpha 6^{+}$ HFSCs. BMP signaling was confirmed to maintain the properties of HFSCs by inhibiting their differentiation. We hypothesized that additional BMP2 would prevent CD200 ${ }^{+} \alpha 6^{+}$HFSCs from generating differentiated progeny, thereby increasing the ratio of $\mathrm{CD}^{200^{+}} \alpha 6^{+}$ HFSCs further. First, we loaded the bioactive molecule BMP2 into the LbL nanocoated layer as a sustained release drug carrier to regulate the fate of the human HFSCs, which is essential for evaluating the potential application of LbL technology in SC microenvironment construction. After coating the cells with the first layer of gelatin, we loaded BMP2 into the alginate layer and coated the HFSCs. We then coated the HFSCs with gelatin to obtain LbL(BMP2)-HFSCs (Fig. 6a). To show BMP2 on the cell surface, we incubated each group with anti-BMP2 antibodies. Data showed that only LbL(BMP2)-HFSCs displayed positive results (Fig. 6b). In a physiological environment $(\mathrm{pH}=7.4$, $\left.\mathrm{T}=37{ }^{\circ} \mathrm{C}\right)$, LbL(BMP2)-HFSCs exhibits a time-varying release characteristic for about 7 days (Fig. 6c). Flow cytometry and immunofluorescence staining detected the ratio of $\mathrm{CD} 200^{+} \alpha 6^{+}$HFSC in each group at P2 (Figs. $5 \mathrm{f}$ and $6 \mathrm{~d}$ ). The results showed that the proportion of CD200 ${ }^{+} \alpha 6^{+}$HFSC population in LbL(BMP2)HFSCs + FV was higher than that of LbL-HFSCs + FV 

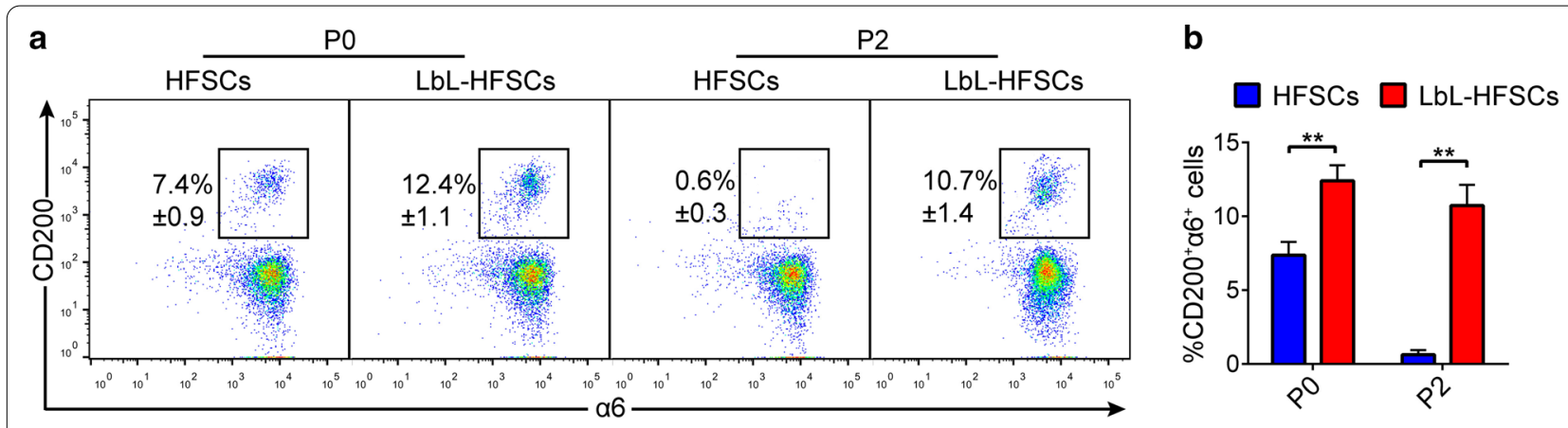

C

PO

P2

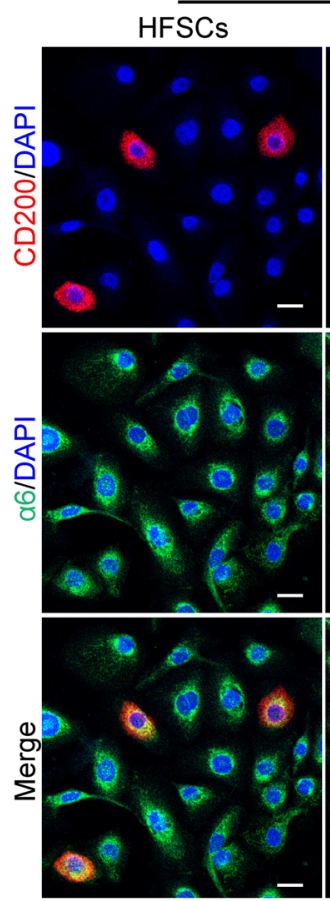
LbL-HFSCs
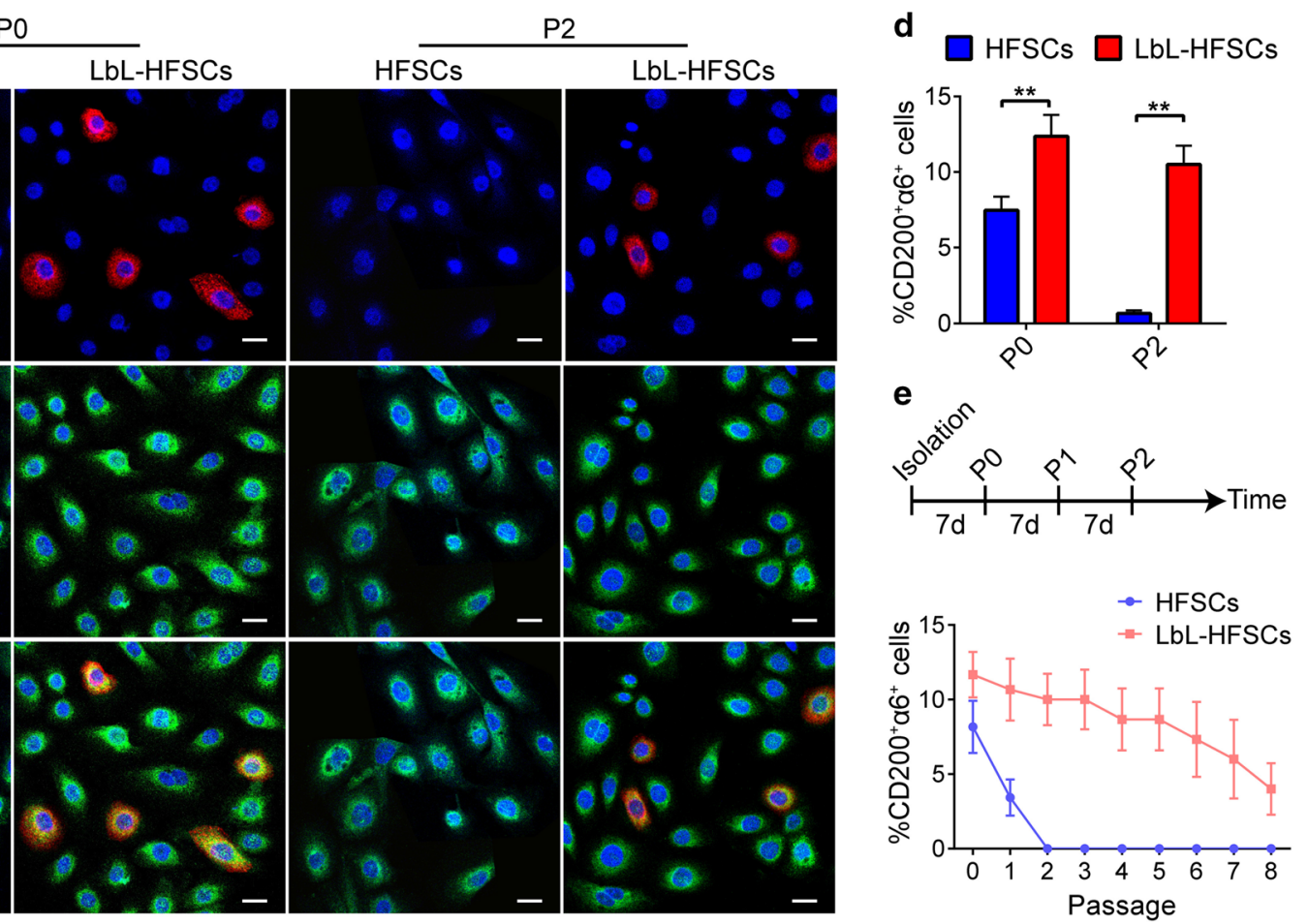

Fig. 4 LbL coating maintained HFSC properties. $\mathbf{a}$, b Flow cytometry was conducted on day 7 after culture. The results showed that the proportion of $\mathrm{CD}_{200^{+}} \mathrm{a}^{+} \mathrm{HFSCs}$ at P0 or P2 in the coated group was higher than the uncoated group (mean $\pm \mathrm{SD} ; \mathrm{n}=3 ;{ }^{* *} p<0.01$, Student's t-test). $\mathbf{c}$, $\mathbf{d}$ Immunofluorescence staining was carried out on day 7 after culture. The proportion of CD200 ${ }^{+} 6^{+} \mathrm{HFSCs}$ at P0 or P2 in the coated group was higher (mean $\pm S D ; n=4 ;{ }^{* *} p<0.01$, Student's t-test). DAPI (blue); CD200 (red); a6 (green); scale bars: $20 \mu \mathrm{m}$. e The long-term cell culture under LbL coating results are from flow cytometry analysis of cells in each passage (mean $\pm S D ; n=3$ )

and LbL-HFSCs + BMP2 + FV (Fig. 6e, g). Collectively, these results demonstrate that compared with the direct addition of BMP2 to the culture medium, the loading of BMP2 can promote the acquisition of the $\mathrm{CD} 200^{+} \alpha 6^{+}$HFSC population. Besides, the absolute number of CD200 ${ }^{+} \alpha 6^{+}$HFSC cells in the LbL(BMP2)HFSCs + FV increased by a factor of eight when cultured to P2 (Additional file 1: Figure S3A). The ratio of $\mathrm{CD}_{200^{+}} \alpha 6^{+}$HFSC cells in the LbL(BMP2)HFSCs + FV remained stable, and could be passaged and expanded for prolonged period (Additional file 1: Figure S3B). These findings confirm that the loading of
BMP2 regulates the fate of human HFSCs more effectively than directly adding BMP2 to obtain a purer CD $200^{+} \alpha 6^{+}$HFSC population.

\section{Discussion}

A fundamental issue in the field of human hair follicle engineering and SC microenvironment research is the construction of a culture model for the stable expansion of human HFSCs and regulation of their fate in vitro. Consistent with previous studies, our results indicate that remodeling the microenvironment of HFSCs in vitro 


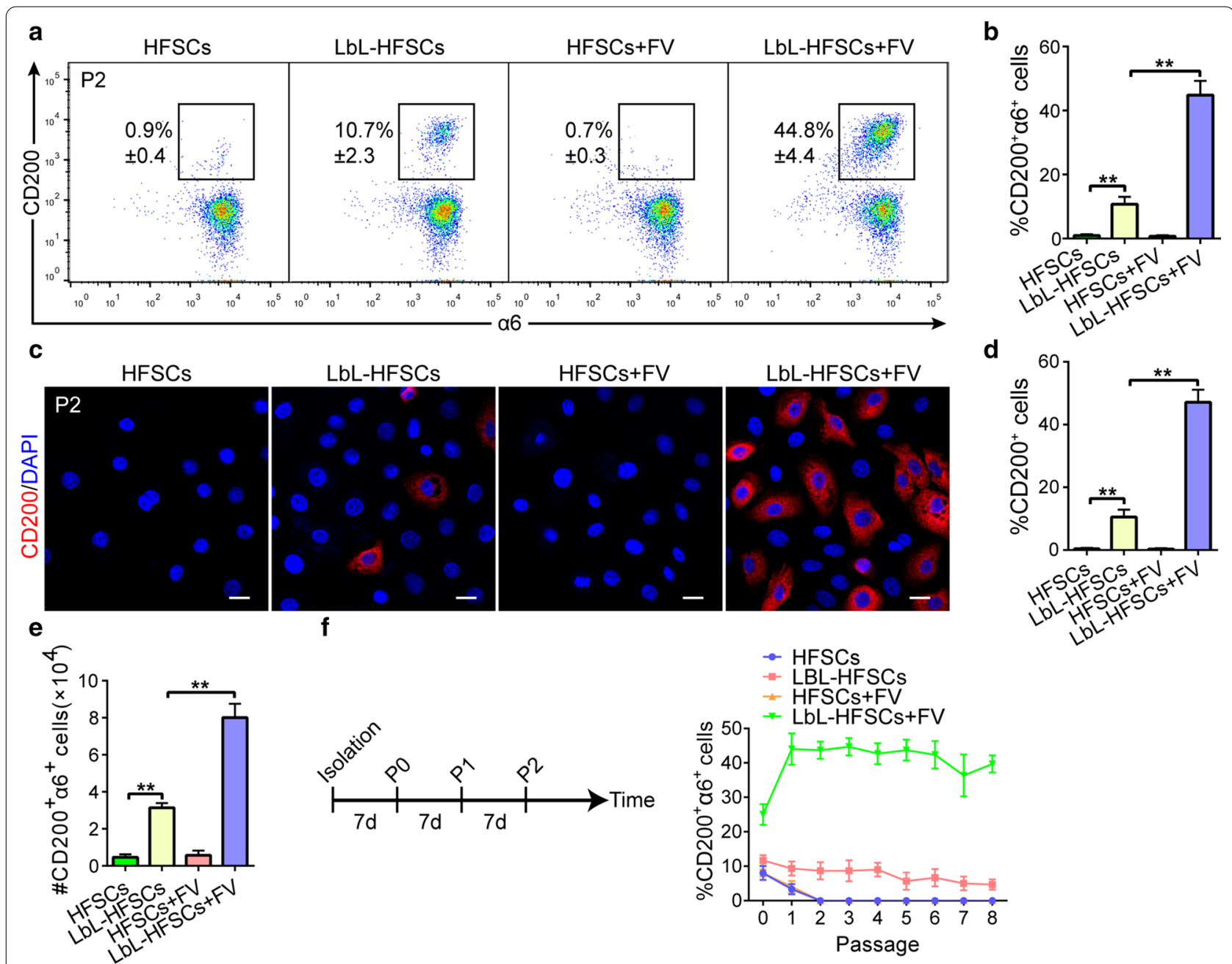

Fig. 5 FGF-7 and VEGF-A stabilize the CD200+ $a 6^{+}$HFSC population. a, b Flow cytometry conducted on the seventh day after culture at P2. The ratio of $C D 200^{+} a 6^{+}$HFSCS in the LbL-HFSCs + FV group was higher than the other groups (mean $\pm S D ; n=3 ;{ }^{* *} p<0.01$, one-way ANOVA). $\mathbf{c}$, d Immunofluorescence staining performed on the seventh day after culture at P2. Red-stained CD200+ HFSCs in the LbL-HFSCs + FV group was higher than the other groups (mean $\pm S D ; n=4 ;{ }^{* *} p<0.01$, one-way ANOVA). DAPI (blue); CD200 (red); scale bars: $20 \mu$ m. e Absolute numbers of CD200 ${ }^{+} 6^{+}$HFSCs at P2 cultured under different conditions, indicated as fold-change relative to the number of cells inoculated at PO (mean \pm SD; $n=4 ;{ }^{* *} p<0.01$, one-way ANOVA). $\mathbf{f}$ The results of the long-term cell culture performed under different conditions are from flow cytometry analysis of cells in each passage. Only the LbL-HFSCs + FV culture maintained a stable CD200 ${ }^{+}$66 ${ }^{+}$HFSC population for an extensive period after P2 (mean $\pm S D ; n=3)$

could maintain the property and plasticity of HFSCs, which is lost under standard 2D culture conditions.

Thus, this study reconstructed a nanoscale biomimetic microenvironment for expanding SCs and revealing their plasticity using LbL self-assembly. As a simple, reliable, efficient, and versatile method, LbL self-assembly technology has been widely used to design and fabricate various nanostructured coatings, films, and scaffolds with tailored physicochemical properties and tunable architectures [25]. This technology has successfully encapsulated and constructed an ECM for various cells, including pancreatic beta cells and neural SCs, thereby promoting their cell function [26, 36]. Here, we employed LbL self-assembly using gelatin and alginate to construct a nanoscale ECM for a single human HFSC. LbL has unique advantages as a technology for constructing a biomimetic ECM for cells at the single-cell level. Our results demonstrate that LbL nanocoating using gelatin and alginate can be applied uniformly in all cells without damaging the HFSC, and helps maintain their SC properties to a certain extent. Additionally, the results of SEM analysis indicated that LbL-HFSC presented a vivo-like 3D structure. This suggests that the LbL nanocoating can provide mechanical support for human HFSCs, keeping them 


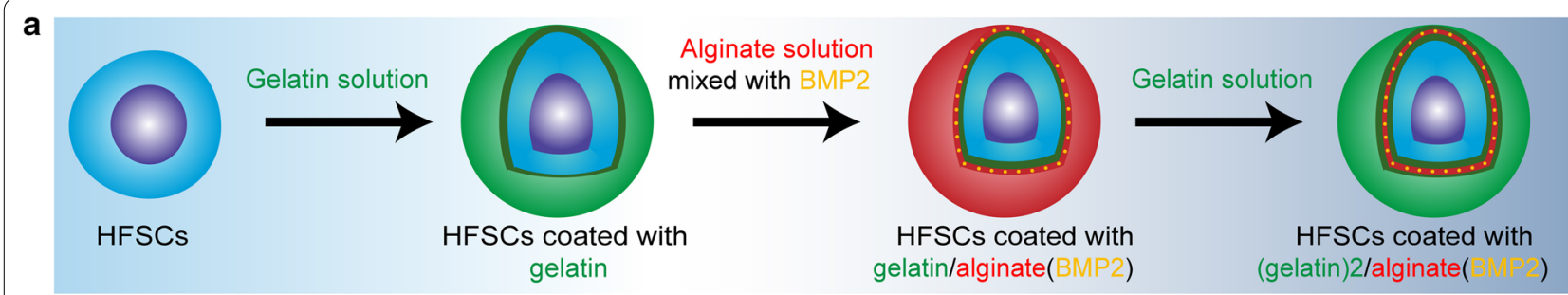

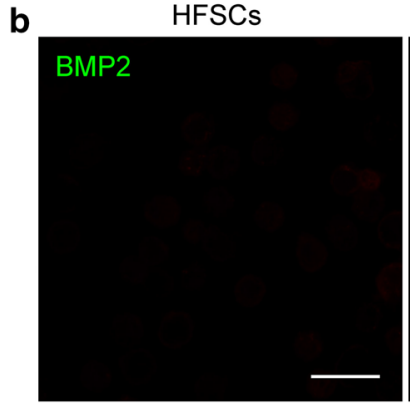

LbL-HFSCs

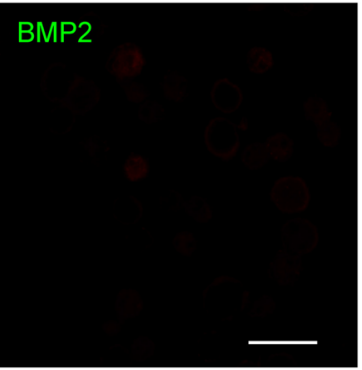

d

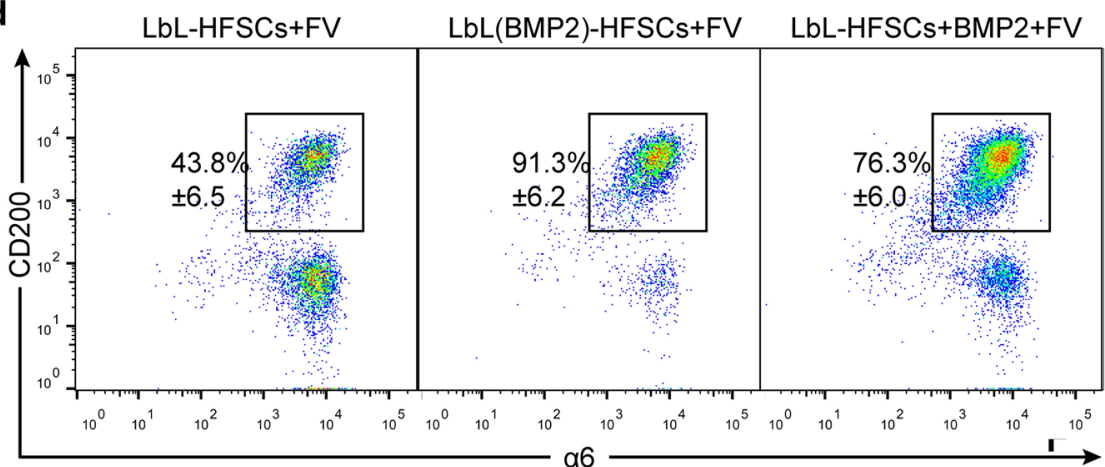

$\mathbf{f}$

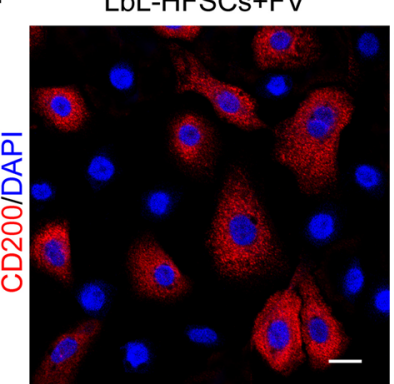

LbL(BMP2)-HFSCs+FV

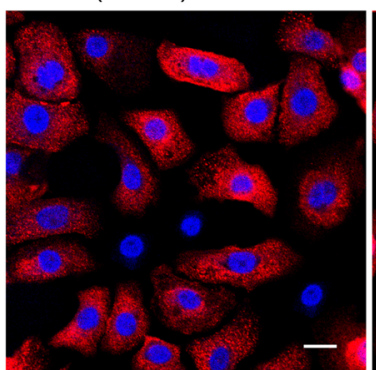

LbL(BMP2)-HFSCs

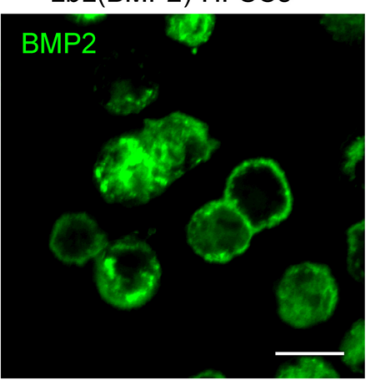

e
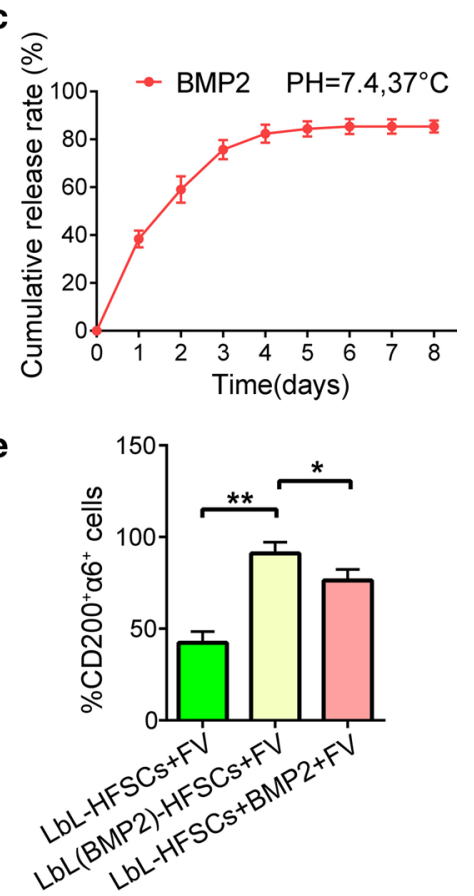

g

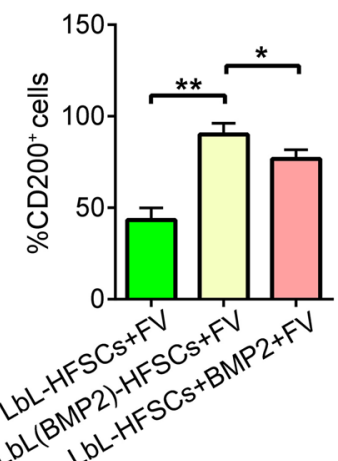

Fig. 6 LbL loading BMP2 mediates CD200+ $6^{+}$HFSC population. a Schematic diagram of LbL(BMP2)-HFSC construction. b Immunofluorescence staining against BMP2, confirming the presence of BMP2 on the cell surface of LbL(BMP2)-HFSCs only. BMP2 (green), scale: $20 \mu \mathrm{m}$. c The release profile of BMP2 conducted using enzyme-linked immunosorbent assay (ELISA) at different time points after coating (mean $\pm S D ; n=4)$. $\mathbf{d}$, e Flow cytometry performed on the seventh day after P2 culture. The proportion of CD200 ${ }^{+} \mathrm{a} 6^{+} \mathrm{HFSC}$ in the LbL(BMP2)-HFSCs + FV group was higher than the other groups (mean $\pm \mathrm{SD} ; \mathrm{n}=3 ;{ }^{*} p<0.05$, ${ }^{* *} p<0.01$, one-way ANOVA). $\mathbf{f}, \mathbf{g}$ Immunofluorescence staining performed on the seventh day after P2 culture. Number of red-stained CD200+ HFSCs in the LbL(BMP2)-HFSCs + FV group was higher than the other groups (mean \pm SD; $n=4$; ${ }^{*} p<0.05,{ }^{* *} p<0.01$, one-way ANOVA). DAPI (blue); CD200 (red); Scale bars: $20 \mu \mathrm{m}$ 
sparsely distributed in a spherical state, alike the in vivo cell microenvironment.

ECM not only regulates cell behavior but also serves as a cell scaffold. Moreover, it plays an essential role in organ development, function, and repair [31]. Some studies have shown that matrix stiffness and its area, rather than ECM composition or concentration, are crucial for the differentiation of keratinocytes, which suggests that biophysical factors are more important in determining the fate of SCs [37]. Moreover, changes in ECM mechanics and cell shape may be transmitted to the nucleus and regulate gene transcription programs [38]. These studies were consistent with our results; the LbL-coating using gelatin/alginate can provide a biomimetic ECM and mechanical support for HFSCs, maintaining their SC properties.

Although the biomimetic ECM composed of gelatin and alginate can maintain the properties of HFSCs to a certain extent, the proportion of CD200 ${ }^{+} \alpha 6^{+}$HFSCs population remains minimal and gradually declines. This indicates that only the coating layer constructed by gelatin and alginate did not satisfy the basic requirements of the SC microenvironment. Studies have shown that besides extracellular proteins, key growth factors are critical for constructing the SC microenvironment [10]. Therefore, we added FGF7 and VEGF2 to the culture medium. Resultantly, the proportion of the CD200 $\alpha 6^{+}$ HFSC population was significantly increased and remained stable after P2, while human HFSCs stably expanded on a large scale. Thus, our results showed that the minimal microenvironment requirement of HFSCs involved ECM and key growth factors.

Lineage tracing and ablation studies have shown that HFSCs are essential for hair regeneration, and the activated progeny refill the ablated SC chamber to sustain hair regeneration [24, 39]. This indicates the plasticity of HFSCs and their progeny in vivo. In other words, the population of CD200 ${ }^{+} \alpha 6^{+}$HFSCs in the bulge area can be re-populated by the CD200- $\alpha 6+$ HFSCs in the nonbulge area. Studies have also confirmed that the plasticity of mouse HFSCs is regulated by BMP and Shh signals in vitro. This study used the LbL nanocoating as a sustained-release drug carrier and loaded the active factorBMP2 to further regulate the fate of HFSCs to reveal the plasticity of human HFSCs in vitro. Our results showed that the proportion of CD200 ${ }^{+} \alpha 6^{+}$HFSCs increased significantly after loading BMP2, reaching $90 \%$. This lays the foundation for the expansion of specific types of purified HFSCs. Besides, by directly separating the ORSCs for culturing, and regulating their fate to obtain a purified population of $\mathrm{CD}^{2} 20^{+} \alpha 6^{+}$HFSCs, the expansion efficiency and use of HFSCs are highly improved. This avoids the waste of precious human hair follicle tissue amplified by $\mathrm{CD} 200^{+} \alpha 6^{+}$HFSCs and purified by FACS, as occurred in previous studies.

Using our innovative biomimetic culture system, we successfully constructed the minimum necessary components for the microenvironment of human HFSCs. This method can not only stably expand human HFSCs but also regulate their fate to reveal their plasticity. This culture system provides an important research avenue for human hair follicle engineering and SC microenvironment research.

\section{Conclusions}

Studies on good culture models that can steadily augment human HFSCs on a large scale with control remain of growing interest in tissue hair follicle engineering and SC homeostasis. Here, we constructed a 2D biomimetic culture system using LbL self-assembly with gelatin and alginate. The system included a biomimetic ECM and some key signal molecules to minimize the niche of simulated SCs, which effectively and stably expanded HFSCs. Loading BMP2 to the LbL nanocoated layer can regulate the plasticity of human HFSCs to obtain purified $\mathrm{CD} 200^{+} \alpha 6^{+}$HFSC populations. This system can simulate the microenvironment of HFSCs more reasonably and comprehensively, thus stably amplifying HFSCs and revealing their plasticity, providing a novel method for hair follicle reconstruction and SC microenvironment research.

\section{Methods \\ Cell cultures}

With the approval of the Medical Ethical Committee of Southern Medical University, after obtaining informed consent, the human hair follicles were obtained from the hair transplantation surgery by follicular unit extraction (FUE). Single HF was dissected and separated from the follicular unit using microforceps under a stereoscope. The lower part (hair papilla area) and the upper part (above the sebaceous glands) of the hair follicle were removed, and the remaining hair follicle tissue was digested with $0.1 \%$ dispersed TICs (theca-interstitial cells) preparations and intact follicles (Invitrogen Biotech, Carlsbad, CA, USA) for $50 \mathrm{~min}$ and shaken every $15 \mathrm{~min}$ at $37^{\circ} \mathrm{C}$. Then the dermal sheath under the stereoscope was removed and the remaining hair follicles containing the outer root sheath were digested by trypsin (0.05\%; Gibco, Gaithersburg, Maryland, USA) for $10-15 \mathrm{~min}$ at $37^{\circ} \mathrm{C}$. To terminate digestion, the same amount of DMEM containing 10\% fetal bovine serum (FBS; Gibco) was added and the cells were filtered with a $70 \mu \mathrm{m}$ filter (Corning, New York, USA). The cell filtrate was subsequently centrifuged at $350 \times g$ for $5 \mathrm{~min}$, and then washed twice with DMEM. For 2D culture of human 
HFSCs, collagen I (30 $\mu \mathrm{g} / \mathrm{mL}$; Millipore) and fibronectin $(10 \mu \mathrm{g} / \mathrm{mL}$; Millipore) in a T25 culture flask were coated in advance at $37{ }^{\circ} \mathrm{C}$ for $1 \mathrm{~h}$, then the cells were re-suspended in KGM medium and inoculated on a T25 culture flask. For the LbL culture of human HFSCs, HFSCs were coated with gelatin and alginate, and the cells were re-suspended in KGM medium and cultured in a T25 culture flask pre-coated with Geltrex (Gibco).

\section{Flow cytometry}

The cell suspension was washed twice in KGM medium and stained with $10 \mu \mathrm{L}$ fluorescent labeled antibody APC-CD200 (Abcam; Cambridge, MA, USA) at $4{ }^{\circ} \mathrm{C}$ and PE-a6 integrin (Abcam) for $20 \mathrm{~min}$. HFSCs cell suspension was washed twice with buffer and analyze under LSRFortessa (BD Biosciences, San Jose, CA, USA). Use FlowJo software version 10 (BD Biosciences) for subsequent data analysis.

\section{LbL coating of single HFSC}

The human HFSCs $(2 \times 106)$ cell suspension was transferred into $15 \mathrm{~mL}$ tube and centrifuged at $350 \times g$ for $5 \mathrm{~min}$. Then, $0.1 \%$ gelatin $(2 \mathrm{~mL}$; Thermo Fisher Scientific, Waltham, Massachusetts, USA) was added to the supernatant, mixed thoroughly and incubated on ice for about $10 \mathrm{~min}$ with repeated shaking. The supernatant was removed after centrifugation at $350 \times g$ centrifugation for $5 \mathrm{~min}$. Subsequently, the cell precipitate was washed twice with DPBS ( $5 \mathrm{~mL}$; Gibco) and $0.1 \%$ alginate $(2 \mathrm{~mL}$; Thermo Fisher Scientific) solution was then added. As mentioned above, the HFSCs were incubated for another $10 \mathrm{~min}$. The supernatant was removed after centrifugation for $5 \mathrm{~min}$ at $350 \times \mathrm{g}$. The entire process was repeated to add another layer of gelatin on HFSCs, and finally, the HFSCs were coated with three layers of biomimetic material.

\section{Preparation of fluorescence-labeled materials}

Commercial FITC-gelatin was acquired from Invitrogen. The preparation of rhodamine $\mathrm{B}$ conjugated-alginate was as follows. First, rhodamine B (20 mg; Invitrogen) added to $2 \mathrm{~mL}$ DPBS; then, 1-ethyl-3-(3 (dimethylamino) propyl) carbodiimide (EDC; $40 \mathrm{mg}$; Thermo Fisher Scientific) and 1-hydroxy-2-line 5-pyrrolidine dione (NHS; $1.75 \mathrm{mg}$; Thermo Fisher Scientific) were added; the sample was incubated at room temperature $\left(25 \pm 1{ }^{\circ} \mathrm{C}\right)$ for $30 \mathrm{~min}$. Ethylenediamine was subsequently added and the sample incubated for $12 \mathrm{~h}$. After dialysis and freeze-drying, rhodamine B-ethylenediamine powder was dissolved in $1 \%$ alginate solution $(2 \mathrm{~mL})$ and adding EDC (10 mg). The solution was oscillated overnight at room temperature, dialyzed, and freeze-dried to obtain rhodamine B-alginate powder.

\section{Scanning electron microscopy (SEM)}

The samples were fixed using $2.5 \%$ glutaraldehyde $(1 \mathrm{~mL})$, and then dehydrated in ethanol. After platinum coating, JSM-6330F (JEOL, Tokyo, Japan) was used to characterize HFSCs and LbL-HFSCs.

\section{Zeta-potential assessment}

We separately collected the uncoated HFSCs, HFSCs coated by gelatin, HFSCs coated by gelatin/alginate, or the HFSCs coated by (gelatin) 2/alginate. A Zetasizer Nano ZS (Malvern Instruments, Malvern, England) was used to determine the zeta potentials of the four groups.

\section{Live/dead staining}

According to the reagent instructions, all samples were stained for $15 \mathrm{~min}$ using living/dead cell-staining (Invitrogen). A fluorescence microscope (IX71 FL, Olympus, Tokyo, Japan) was used to visualize images.

\section{Cloning formation assay}

HFSCs/well $\left(1 \times 10^{3}\right.$ cells/well $)$ were cultured for 14 days in 6-well plates pre-coated with a mixture of collagen I and fibronectin, or Geltrex. Colonies were then stained with Giemsa Stain and counted for their colony number.

\section{Immunofluorescence}

After washing once with DPBS, the cells were fixed with $4 \%$ paraformaldehyde at room temperature for $15 \mathrm{~min}$, and $0.3 \%$ Triton $\mathrm{X}$ was permeated for $5 \mathrm{~min}$. After blocking the samples for 30 min with 5\% BSA, the samples were incubated with the primary antibody against CD200 (1:200, Abcam), a6 (1:100, Abcam) or BMP2 (1:100, Abcam) overnight at $4{ }^{\circ} \mathrm{C}$. The cells were stained with fluorescent secondary antibody at room temperature for $1 \mathrm{~h}$ and DPAI for $5 \mathrm{~min}$. Fluorescence microscope images were obtained using CLSM (LSM880, Cari Zeiss, Jena, Germany).

\section{BMP2 loading and ELISA}

For the loading of BMP2 (Abcam), we followed the same procedure as that for LbL cell coating, except that $100 \mathrm{ng} /$ $\mathrm{mL}$ BMP2 was added to $1 \mathrm{~mL} 0.1 \%$ alginate and loaded into the second nanocoated layer. For ELISA, samples $(20 \mathrm{~mL})$ obtained at specified time points were added to a microwell plate pre-coated with anti- BMP2 for $2 \mathrm{~h}$. Subsequently, each well was added to the conjugated solution for $1.5 \mathrm{~h}$, and the solution was added to the culture plate for $25 \mathrm{~min}$. After that, the termination solution added. A 
multi-label counter was used to measure absorbance at $450 \mathrm{~nm}$.

\section{Quantitative real-time polymerase chain reaction (qRT-PCR)}

Total RNA was extracted from HFSCs with TRIzol (Invitrogen) and then reverse transcribed with PrimeScript ${ }^{\circledR}$ RT reagent (Takara Bio, Shiga, Japan). Using the Stratagene MX3005P qRT-PCR system (Agilent Technologies, Santa Clara, CA, USA), we followed the manufacturer's operating procedures for qRT-PCR. The primer sequence is listed in Additional file 1: Table S1.

\section{Western blotting}

Proteins were extracted using a lysis buffer and quantified using a BCA Protein Assay Kit (Thermo Fisher Scientific, West Palm Beach, FL). The protein lysate was electrophoresed using 10\% SDS-PAGE and transferred to a PVDF membrane (Roche). The membranes were incubated with primary antibodies CD200 (1:1,000, Abcam) at $4{ }^{\circ} \mathrm{C}$ overnight. After washing, secondary antibodies were labeled with HRP, and the signals were photographed. The band intensity of the protein was determined by densitometry using ImageJ software. GAPDH served as the loading control.

\section{Statistical analysis}

Statistical analyses were conducted using SPSS software (SPSS, version 18.0) or GraphPad Prism software (GraphPad, version 7.0). Statistical significance was determined using the Student's t-test or the one-way analysis of variance (ANOVA). The data were expressed as mean \pm standard deviation (SD). Each experiment was performed at least three times. $\mathrm{p}<0.05$ was considered significant.

\section{Abbreviations}

ECM: Extracellular matrix; FUE: Follicular unit extraction; FACS: Fluorescenceactivated cell sorting; HFSCs: Hair follicle stem cells; KGM: Keratinocyte growth medium; LbL: Layer-by-layer; ORSCs: Outer root sheath cells; SCs: Stem cells; SEM: Scanning electron microscopy; qRT-PCR: Quantitative real-time polymerase chain reaction.

\section{Supplementary Information}

The online version contains supplementary material available at https://doi. org/10.1186/s12951-021-00840-5.

Additional file 1: Table S1. Primers used for quantitative real-time polymerase chain reaction. Figure S1. Colony formation assay analysis of cell proliferation. Figure S2. SC properties of LbL-HFSCs. Figure S3. Long-term culture of HFSCS under different conditions.

Acknowledgements

Not applicable.

\section{Authors' contributions}

PC and FZ designed the study and performed majority of the experiments, analyzed the data, and wrote the manuscript. YM and JW isolated, expanded, and cultured HFSCs from donor samples. ZH designed the study and reviewed the manuscript. All authors read and approved the final manuscript.

\section{Funding}

This work was supported by the Natural Science Foundation of Guangdong Province (Grant No. 2019A1515012170, No. 2017A030310120), the Natural Science Foundation of China (Grant No. 81772104, No. 81902013, No. 81971889, No. 81701929).

\section{Availability of data and materials}

All data and materials are included in the manuscript.

\section{Declarations}

Ethics approval and consent to participate

All experiments were carried out with the approval of the Medical Ethical Committee of Southern Medical University. Informed consent was obtained from participants.

\section{Consent for publication}

All authors have provided consent for the manuscript to be published.

\section{Competing interests}

There are no conflicts of interest to declare.

Received: 7 January 2021 Accepted: 23 March 2021

Published online: 31 March 2021

\section{References}

1. Blanpain C, Fuchs E. Stem cell plasticity. Plasticity of epithelial stem cells in tissue regeneration. Science (New York, NY). 2014;344(6189):1242281.

2. Donati G, Watt FM. Stem cell heterogeneity and plasticity in epithelia. Cell Stem Cell. 2015;16(5):465-76.

3. Koren E, Yosefzon Y, Ankawa R, Soteriou D, Jacob A, Nevelsky A, et al. ARTS mediates apoptosis and regeneration of the intestinal stem cell niche. Nat Commun. 2018;9(1):4582.

4. Lu Z, Xie Y, Huang H, Jiang K, Zhou B, Wang F, et al. Hair follicle stem cells regulate retinoid metabolism to maintain the self-renewal niche for melanocyte stem cells. Elife. 2020;9:e52712.

5. Quan R, Zheng X, Ni Y, Xie S, Li C. Culture and characterization of rat hair follicle stem cells. Cytotechnology. 2016;68(4):621-8.

6. Chapman S, Liu X, Meyers C, Schlegel R, McBride AA. Human keratinocytes are efficiently immortalized by a Rho kinase inhibitor. J Clin Invest. 2010;120(7):2619-26.

7. An L, Ling P, Cui J, Wang J, Zhu X, Liu J, et al. ROCK inhibitor Y-27632 maintains the propagation and characteristics of hair follicle stem cells. Am J Transl Res. 2018;10(11):3689-700.

8. Hazeltine LB, Selekman JA, Palecek SP. Engineering the human pluripotent stem cell microenvironment to direct cell fate. Biotechnol Adv. 2013;31(7):1002-19.

9. Li L, Xie T. Stem cell niche: structure and function. Annu Rev Cell Dev Biol. 2005;21:605-31.

10. Chacón-Martínez CA, Klose M, Niemann C, Glauche I, Wickström SA. Hair follicle stem cell cultures reveal self-organizing plasticity of stem cells and their progeny. EMBO J. 2017;36(2):151-64.

11. Chen P, Miao Y, Zhang F, Huang J, Chen Y, Fan Z, et al. Nanoscale microenvironment engineering based on layer-by-layer self-assembly to regulate hair follicle stem cell fate for regenerative medicine. Theranostics. 2020;10(25):11673-89.

12. Sousa MP, Arab-Tehrany E, Cleymand F, Mano JF. Surface micro- and nanoengineering: applications of layer-by-layer technology as a versatile tool to control cellular behavior. Small. 2019;15(30):e1901228. 
13. Guo S, Zhu X, Loh XJ. Controlling cell adhesion using layer-by-layer approaches for biomedical applications. Mater Sci Eng C Mater Biol Appl. 2017;70(Pt 2):1163-75.

14. Feng Y, Li X, Guo S, Chen X, Chen T, He Y, et al. Extracellular silica nanocoat formed by layer-by-layer ( $L B L$ ) self-assembly confers aluminum resistance in root border cells of pea (Pisum sativum). J Nanobiotechnol. 2019:17(1):53.

15. Svenskaya YI, Genina EA, Parakhonskiy BV, Lengert EV, Talnikova EE, Terentyuk GS, et al. A simple non-invasive approach toward efficient transdermal drug delivery basedon biodegradable particulate system. ACS Appl Mater Inter. 2019;11(19):17270-82.

16. Elzoghby AO. Gelatin-based nanoparticles as drug and gene delivery systems: reviewing three decades of research. J Control Release. 2013;172(3):1075-91.

17. Liu G, Li L, Huo D, Li Y, Wu Y, Zeng L, et al. A VEGF delivery system targeting $\mathrm{Ml}$ improves angiogenesis and cardiac function based on the tropism of MSCs and layer-by-layer self-assembly. Biomaterials. 2017;127:117-31.

18. Villar-Alvarez E, Cambón A, Pardo A, Arellano L, Marcos AV, Pelaz B, et al. Combination of light-driven co-delivery of chemodrugs and plasmonicinduced heat for cancer therapeutics using hybrid protein nanocapsules. J Nanobiotechnol. 2019;17(1):106.

19. Silva JM, Reis RL, Mano JF. Biomimetic extracellular environment based on natural origin polyelectrolyte multilayers. Small. 2016;12(32):4308-42.

20. Wang J, Miao Y, Huang Y, Lin B, Liu X, Xiao S, et al. Bottom-up nanoencapsulation from single cells to tunable and scalable cellular spheroids for hair follicle regeneration. Adv Healthc Mater. 2018;7(3):1700447.

21. Rosellini E, Zhang YS, Migliori B, Barbani N, Lazzeri L, Shin SR, et al. Protein/polysaccharide-based scaffolds mimicking native extracellular matrix for cardiac tissue engineering applications. J Biomed Mater Res A. 2018;106(3):769-81.

22. Luo C, Fang H, Zhou M, Li J, Zhang X, Liu S, et al. Biomimetic open porous structured core-shell microtissue with enhanced mechanical properties for bottom-up bone tissue engineering. Theranostics. 2019;9(16):4663-77

23. Cheng T, Zhang Z, Shen H, Jian Z, Li J, Chen Y, et al. Topically applicated curcumin/gelatin-blended nanofibrous mat inhibits pancreatic adenocarcinoma by increasing ROS production and endoplasmic reticulum stress mediated apoptosis. J Nanobiotechnol. 2020;18(1):126.

24. Rompolas P, Mesa KR, Greco V. Spatial organization within a niche as a determinant of stem-cell fate. Nature. 2013:502(7472):513-8.

25. Liu T, Wang Y, Zhong W, Li B, Mequanint K, Luo G, et al. Biomedical applications of layer-by-layer self-assembly for cell encapsulation: current status and future perspectives. Adv Healthc Mater. 2019;8(1):e1800939.

26. Li W, Guan T, Zhang X, Wang Z, Wang M, Zhong W, et al. The effect of layer-by-layer assembly coating on the proliferation and differentiation of neural stem cells. ACS Appl Mater Interfaces. 2015;7(5):3018-29.
27. Morgner J, Ghatak S, Jakobi T, Dieterich C, Aumailley M, Wickström SA. Integrin-linked kinase regulates the niche of quiescent epidermal stem cells. Nat Commun. 2015;6:8198.

28. Speziale P, Arciola CR, Pietrocola G. Fibronectin and its role in human infective diseases. Cells-Basel. 2019;8(12):1516.

29. Sarantopoulos CN, Banyard DA, Ziegler ME, Sun B, Shaterian A, Widgerow AD. Elucidating the preadipocyte and its role in adipocyte formation: a comprehensive review. Stem Cell Rev Rep. 2018;14(1):27-42.

30. Chermnykh E, Kalabusheva E, Vorotelyak E. Extracellular matrix as a regulator of epidermal stem cell fate. Int J Mol Sci. 2018;19(4):1003.

31. Trappmann B, Gautrot JE, Connelly JT, Strange DGT, Li Y, Oyen ML, et al. Extracellular-matrix tethering regulates stem-cell fate. Nat Mater. 2012;11(7):642-9.

32. Bronzino JD, Schaffer DV, Peterson DR. Stem cell engineering: principles and practices. Boca Raton: CRC Press; 2013.

33. Kozlowska U, Blume-Peytavi U, Kodelja V, Sommer C, Goerdt S, Majewski $\mathrm{S}$, et al. Expression of vascular endothelial growth factor (VEGF) in various compartments of the human hair follicle. Arch Dermatol Res. 1998;290(12):661-8.

34. Plikus MV, Chuong C. Macroenvironmental regulation of hair cycling and collective regenerative behavior. CSH Perspect Med. 2014;4(1):a15198.

35. Ozeki M, Tabata Y. Promoted growth of murine hair follicles through controlled release of vascular endothelial growth factor. Biomaterials. 2002;23(11):2367-73.

36. Fukuda Y, Akagi T, Asaoka T, Eguchi H, Sasaki K, Iwagami Y, et al. Layer-bylayer cell coating technique using extracellular matrix facilitates rapid fabrication and function of pancreatic beta-cell spheroids. Biomaterials. 2018;160:82-91.

37. Connelly JT, Gautrot JE, Trappmann B, Tan DW, Donati G, Huck WTS, et al. Actin and serum response factor transduce physical cues from the microenvironment to regulate epidermal stem cell fate decisions. Nat Cell Biol. 2010;12(7):711-8

38. Mammoto A, Mammoto T, Ingber DE. Mechanosensitive mechanisms in transcriptional regulation. J Cell Sci. 2012;125(Pt 13):3061-73.

39. Hsu Y, Li L, Fuchs E. Emerging interactions between skin stem cells and their niches. Nat Med. 2014;20(8):847-56.

\section{Publisher's Note}

Springer Nature remains neutral with regard to jurisdictional claims in published maps and institutional affiliations.
Ready to submit your research? Choose BMC and benefit from:

- fast, convenient online submission

- thorough peer review by experienced researchers in your field

- rapid publication on acceptance

- support for research data, including large and complex data types

- gold Open Access which fosters wider collaboration and increased citations

- maximum visibility for your research: over $100 \mathrm{M}$ website views per year

At BMC, research is always in progress.

Learn more biomedcentral.com/submissions 